\title{
Nicotine Patch
}

National Cancer Institute

\section{Source}

National Cancer Institute. Nicotine Patch. NCI Thesaurus. Code C17955.

A transdermal patch containing the alkaloid nicotine with nicotine replacement activity. Upon administration of the patch, nicotine is slowly released into the bloodstream and, although nicotine binds to nicotinic cholinergic receptors at the autonomic ganglia, adrenal medulla and at neuromuscular junctions as well, the binding of nicotine to the receptors in the central nervous system (CNS) appears to be responsible for the addictive nature of nicotine. Binding to CNS nicotinic acetylcholine receptors causes the release of the neurotransmitter dopamine which appears to be responsible for the addiction of nicotine. Administration of nicotine may prevent nicotine craving and may help with the withdrawal symptoms associated with smoking cessation. 